\title{
Evaluation of Phosphate Solubilizing Potential of Three Burkholderia Species Isolated from Green House Soils
}

\author{
Buddhi Charana Walpola, June-Seob Song, Mi-Jung Keum, and Min-Ho Yoon* \\ College of Agriculture and Life Sciences, Chungnam National University, Daejeon, 305-764, Korea
}

\begin{abstract}
Burkholderia anthina R-4183, Burkholderia diffusa R-15930 and Burkholderia stabilis LMG 14294 isolated from green house soils (Gongju-Gun area, South Korea) were characterized and their phosphate solubilizing ability was assessed. Under in vitro culture conditions, all three species were proved to be effective in solubilizing phosphates in varying degrees. Strain Burkholderia anthina exhibited the highest phosphate solubilization in NBRIP medium $\left(665 \mu \mathrm{g} \mathrm{ml}^{-1}\right)$ followed by Burkholderia diffusa $\left(630 \mu \mathrm{g} \mathrm{ml}^{-1}\right)$ and Burkholderia stabilis $\left(578 \mu \mathrm{g} \mathrm{ml}^{-1}\right)$. However, solubilization of $\mathrm{FePO}_{4}$ and $\mathrm{AlPO}_{4}$ was found to be poor in all the strains. Acidification by means of gluconic and oxalic acids accumulation in the culture medium could be the possible mechanism responsible for phosphate solubilization. Glucose at the rate of $3 \%$ was found be the best carbon source for Burkholderia anthina while other two Burkholderia species showed maximum phosphate solubilization at $2 \%$ of glucose. In the case of nitrogen sources, ammonium and nitrate were equally effective in solubilizing phosphates by Burkholderia species. Despite a slight decrease in phosphate solubilization observed at increasing temperature, all three Burkholderia species could withstand a temperature of $30-35^{\circ} \mathrm{C}, \mathrm{pH}$ at the range of 7-9 and the presence of $\mathrm{NaCl}$ (up to $2.5 \%$ ) without much compromising the phosphate solubilization. As shown with potted mung bean seedlings, all the three isolates could enhance soil fertility and plant growth indicating their great potential to be used as bio-inoculants.
\end{abstract}

Key words: Phosphate Solubilization, Burkholderia species, Acidification

\section{Introduction}

Phosphorus is one of the major essential macronutrients for plant growth and it is applied as chemical fertilizer. However, a large portion of the applied soluble forms of phosphorus fertilizers are easily immobilized in to insoluble forms particularly, $\mathrm{CaHPO}_{4}, \mathrm{Ca}_{3}\left(\mathrm{PO}_{4}\right)_{2}, \mathrm{FePO}_{4}$ and $\mathrm{AlPO}_{4}$ and then become unavailable to plants (Mundra et al., 2011). Therefore, most soils are deficient in soluble forms of phosphorus. This leads to an excess application to crop plants and continuous application of phosphate fertilizers cause economical and environmental problem due to soil and water pollution (Park et al., 2010).

There are some microorganisms effectively involved in the solubilization of insoluble phosphate (Vassilev et al., 2006) called as phosphate solubilizing microorganisms (PSMs). Recently, PSMs have attracted the attention of agriculturists to apply them to soil as bio-inoculants to

\footnotetext{
Received : 2012. 7. 18 Accepted : 2012. 8. 16

*Corresponding author : Phone: +82428216733

E-mail: mhyoon@cnu.ac.kr
}

mitigate the phosphate problems (Fasim et al., 2002).

Solubilization of phosphate by PSMs depends on various physico-chemical factors viz. nature and amount of phosphate sources, $\mathrm{pH}$, temperature, salt and acid concentration. Apart from this, carbon and nitrogen sources and their concentrations also have strong influence on phosphate solubilization (Dave and Patel, 2003). Therefore effective phosphate solubilization mainly depends on optimum combination of various physicochemical factors along with the energy sources.

Previous studies have demonstrated that the ability of some Burkholderia species to efficiently solubilize inorganic phosphates, which subsequently results in increased availability of phosphorus for plants (Lin et al., 2006; Song et al., 2008). In present study three Burkholderia species having potential to solubilize insoluble phosphates were isolated from green house soils in South Korea and their characteristics of phosphate solubilization were investigated. In addition, the capacity of these isolates as bio-inoculants was assessed in pot experiments. 


\section{Materials and Methods}

Isolation of strain Bacterial strains were isolated from the soils collected from Chungchugnam-do province, Gongju-Gun area in South Korea. Serial dilution of soil solution were spread on NBRIP (National Botanical Research Institute Phosphorus) agar plates containing $10 \mathrm{~g}$ glucose, $5 \mathrm{~g} \mathrm{Ca}_{3}\left(\mathrm{PO}_{4}\right)_{2}, 5 \mathrm{~g} \mathrm{MgCl} 2.6 \mathrm{H}_{2} \mathrm{O}, 0.25 \mathrm{~g} \mathrm{MgSO}_{4}$. $7 \mathrm{H}_{2} \mathrm{O}, 0.2 \mathrm{~g} \mathrm{KCl}, 0.1 \mathrm{~g}\left(\mathrm{NH}_{4}\right)_{2} \mathrm{SO}_{4}$ in $1 \mathrm{~L}$ distilled water (Nautiyal, 2000). The plates were incubated for 5 days at $30^{\circ} \mathrm{C}$. Formation of clear halo zone around the colonies after 5 days of incubation indicates phosphate solubilizing ability. It was further purified by re-culturing on the fresh NBRIP agar plates.

\section{S IDNA gene sequencing and Phylogenetic} analysis of the isolated bacteria The partial sequencing of 16S rRNA of the strains was done with the help of DNA sequencing service, SOLGENT, Daejeon, South Korea using universal primers, $27 \mathrm{~F}$ and 1492R. The online program BLAST was used to find out the related sequences with known taxonomic information available at the databank of NCBI (http://www.ncbi.nlm.nih.gov/ BLAST). Three Burkholderia species were selected for further studies and a Phylogenetic tree was constructed using CLUSTAL X program, which involved sequence alignment by neighbor joining method and maximum parsimony using the MEGA4 program. Grouping of sequences was based on confidence values obtained by bootstrap analysis of 1,000 replicates. Gaps were edited in the BioEdit program and evolutionary distances were calculated using Kimura two parameter model. Reference sequences were retrieved from GenBank under the accession numbers indicated in the trees.

\section{Assay of Inorganic phosphate solubilizing abilities} Bacterial strains were grown in sterilized liquid NBRIP medium $(20 \mathrm{ml})$ at $30^{\circ} \mathrm{C}$ for 2 days with continuous shaking at $150 \mathrm{r} \mathrm{min}^{-1}$. Aliquots of culture $(1 \mathrm{ml})$ were then transferred to a $500 \mathrm{ml}$ flask ( $\mathrm{n}=3$ per strain) containing sterilized liquid NBRIP medium $(200 \mathrm{ml})$ and incubated for 7 days with continuous shaking at $30^{\circ} \mathrm{C}$. Sterilized uninoculated medium served as a control. A sample (10 $\mathrm{ml}$ ) of each cultured and control were taken daily and centrifuged at $8000 \mathrm{rpm}$ for $15 \mathrm{~min}$. The clear supernatant was used in determining the amount of phosphorous released into the medium. The $\mathrm{pH}$ of the culture medium was also recorded with the $\mathrm{pH}$ meter equipped with glass electrode. The phosphorus availability was determined using phospho-molybdate blue color method (Murphy and Riley, 1962).

For the analysis of organic acids, $10 \mu \mathrm{l}$ of filtrate was injected to high-performance liquid chromatography. The used column was Inertsil ODS $3 \mathrm{~V}$ and a UV detector set to $210 \mathrm{~nm}$ at $40^{\circ} \mathrm{C}$. Mobile phase consisted of $0.008 \mathrm{M}$ $\mathrm{H}_{2} \mathrm{SO}_{4}$ run at a flow rate of $0.2 \mathrm{ml} \mathrm{min}^{-1}$. HPLC profiles of the culture filtrates were analyzed by comparison with the elution profiles of pure organic acids (gluconic acid, oxalic acid and citric acid) injected separately. Peaks were identified by retention times against a set of standards from known three organic acids.

The $\mathrm{Ca}_{3}\left(\mathrm{PO}_{4}\right)_{2}$ solubilization assay performed as described above and $\mathrm{AlPO}_{4}$ and $\mathrm{FePO}_{4}$ solubilization was assayed by adding $4 \mathrm{~g} \mathrm{l}^{-1} \mathrm{AlPO}_{4}$ or $6 \mathrm{~g} \mathrm{l}^{-1} \mathrm{FePO}_{4} \cdot 2 \mathrm{H}_{2} \mathrm{O}$ instead of $\mathrm{Ca}_{3}\left(\mathrm{PO}_{4}\right)_{2}$ in NBRIP medium. Rock phosphate solubilization ability was assayed using rock phosphate having $\mathrm{P}_{2} \mathrm{O}_{5}$ content $28 \%$ instead of $\mathrm{Ca}_{3}\left(\mathrm{PO}_{4}\right)_{2}$ in NBRIP medium. These amounts are equal to phosphorus as in the standard NBRIP medium.

Phosphate solubilizing ability of bacterial strains was tested under different carbon and nitrogen sources. Effect of carbon source on phosphate solubilization was tested by adding fructose, galactose, sorbitol, mannitol, xylose, sucrose, maltose and lactose instead of glucose in the NBRIP medium. To test the effect of the nitrogen source, $\left(\mathrm{NH}_{4}\right)_{2} \mathrm{SO}_{4}$ in the NBRIP medium was replaced byNH $\mathrm{N}_{4} \mathrm{Cl}$, $\mathrm{NH}_{4} \mathrm{NO}_{3}, \mathrm{KNO}_{3}, \mathrm{NaNO}_{3}$ and $\mathrm{Ca}\left(\mathrm{NO}_{3}\right)_{2}$.

The effect of salt on phosphate solubilization was tested by growing the strain on NBRIP containing various amounts of $\mathrm{NaCl}(0 \%, 2.5 \%, 5 \%$ and $10 \%)$. Further, the effect of $\mathrm{pH}$ on phosphate solubilization was tested by adjusting the $\mathrm{pH}$ of NBRIP medium using $\mathrm{HCl}$ or $\mathrm{NaOH}$ to different $\mathrm{pH}$ levels (7-10). For estimation of high temperature induced phosphate solubilization NBRIP medium inoculated strain was incubated at different temperature conditions $\left(30-40^{\circ} \mathrm{C}\right)$. In all cases, phosphate solubilization and $\mathrm{pH}$ of the culture medium were measured described earlier. The absolute value of the control refers to the amount of phosphorus solubilized $(\mu \mathrm{g}$ $\mathrm{ml}^{-1}$ ) by each strain (PSB-1, PSB-2 and PSB-3) when individually grown for 3 days in NBRIP medium under the $30^{\circ} \mathrm{C}$ temperature, $\mathrm{pH} 7$ and in the absence of salt $(\mathrm{NaCl})$.

Plant growth promotion bioassay on mungbean (Vigna radiata) Pot culture assay for plant growth 
promotion ability of the Burkholderia species was determined in sterilized soil for 4 weeks. Seeds of mungbean were soaked in bacterial suspensions separately at the concentration of $10^{8}$ cells ml ${ }^{-1}$ about 30 min prior to plantation. At the end of 4 weeks, seedlings were uprooted, washed under running water and root and shoot length were measured.

Values are given as means $\pm \mathrm{SD}$ for triplicate samples. All the data were analyzed by analysis of variance or by regression analysis. Differences were considered to be significant at the $\mathrm{P} \leq 0.05$ level.

\section{Results and Discussion}

\section{Isolation and Identification of Burkholderia species}

All three Burkholderia species had a marked insoluble phosphate solubilizing ability as visualized by the clear zone developed around the colonies after 5 day incubation at $30^{\circ} \mathrm{C}$. It was seen that halo zone increased with increase in colony diameter. Solubilization Index (colony diameter + halo zone diameter/ colony diameter) was found to be reached to the peak at 5 days after inoculation $(2.75,3.25$ and 2.25 respectively for PSB-1, PSB-2 and PSB-3) followed by gradual reduction.

According to $16 \mathrm{~S}$ rRNA sequence analysis, the strains were identified as Burkholderia anthina R-4183 (PSB-1), Burkholderia diffusa R-15930 (PSB-2) and Burkholderia stabilis LMG 14294 (PSB-3). A phylogenetic tree was constructed with 16S rRNA sequences of strains with

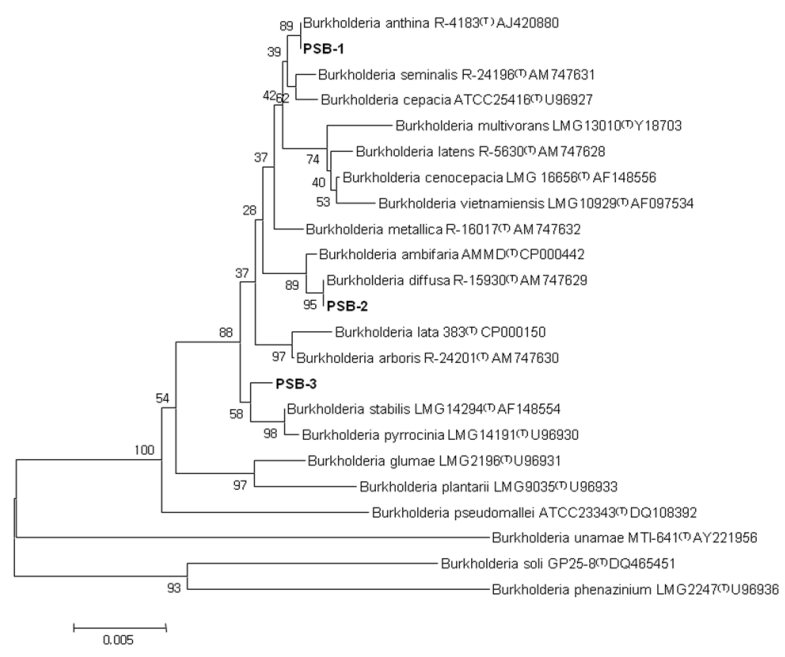

Fig. 1. Phylogenetic tree based on 16S nDNA gene sequences, showing the position of isolated efficient phosphate solubilizing bacterial strains with respect to related species. The scale bar indicates 0.005 substitutions per nucleotide position and accession numbers are given in parenthesis. other Burkholderia species using neighbor-joining method (Fig. 1).

\section{Assay of inorganic phosphate solubilizing abilities}

Periodic changes of the soluble phosphorus content which has been released from the inorganic phosphorus in the NBRIP medium, due to addition of three Burkholderia inoculants during 7 days of incubation are presented in Fig. 2. Results showed that the isolates had different capabilities to release soluble phosphorus from inorganic phosphate. Among the three isolates, PSB-1was shown to release the highest content of soluble phosphorus $(665 \mu \mathrm{g}$ $\mathrm{ml}^{-1}$ ) into the medium, followed by PSB-2 and PSB-3 with 630 and $578 \mu \mathrm{g} \mathrm{ml}^{-1}$ of soluble phosphorus respectively (Fig. 2). Results also showed that the content of soluble phosphorus released by the isolates in culture medium increased significantly during the first 2 days of the incubation remained high for several days. However subsequently a significant drop in soluble phosphorus level was observed on later days when incubation period progressed. This may be due to the availability of soluble phosphorus in the culture medium, which has an inhibitory effect on further phosphate solubilization (Xiao et al., 2009). Some researchers suggested that it is due to the depletion of nutrients in the culture medium especially carbon source for the production of organic acids and microbial activity (Kang et al., 2002; Kim et al., 2005; Chaiharn and Lumyong, 2009). There was no significant change in the content of soluble phosphorus under the control, which only resulted in a negligible slight increment throughout the incubation period.

All three strains produced acid and lowered the $\mathrm{pH}$ of culture medium from 7 to 3.63-3.93 after one day. Thereafter, the $\mathrm{pH}$ of the medium remained constant for

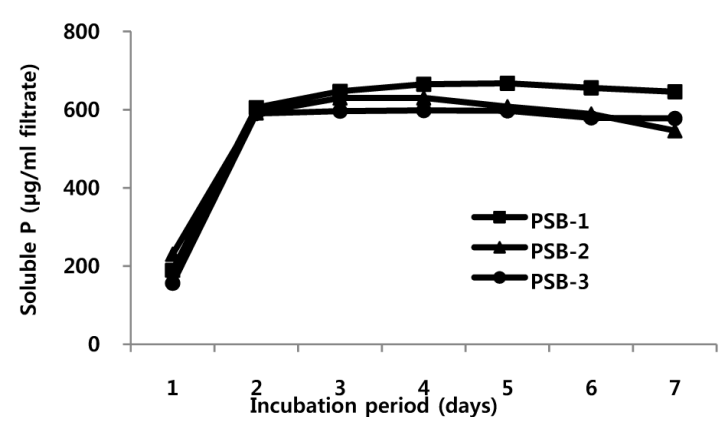

Fig. 2. Soluble phosphorus content in the NBRIP culture medium due to phosphate solubilization by three Burkholderia species. Results represent the mean of three replicates \pm SD. 
Table 1. HPLC analysis of organic acids production by phosphate solubilization by PSB-1, PSB-2 and PSB-3. Values given here are the means of three replicates $(n=3)$.

\begin{tabular}{lcccccccc}
\hline \hline & \multicolumn{4}{c}{ Gluconic acid $\mathrm{mM}$} \\
\cline { 2 - 11 } & Day 1 & Day 2 & Day 3 & Day 4 & Day 1 & Day 2 & Day 3 & Day 4 \\
\hline PSB -1 & 1.12 & 3.19 & 5.59 & 5.29 & 0.007 & 0.009 & 0.012 & 0.009 \\
PSB -2 & 0.02 & 4.97 & 7.98 & 7.71 & 0.075 & 0.099 & 0.117 & 0.101 \\
PSB -3 & 1.16 & 4.87 & 5.78 & 4.51 & 0.003 & 0.004 & 0.006 & 0.004 \\
\hline
\end{tabular}

several days (data not presented). The decrease in $\mathrm{pH}$ clearly indicated the production of organic acids, which is considered to be responsible for phosphate solubilization. Phosphate solubilization was concomitant with a significant $\mathrm{pH}$ decrease and microorganisms which decrease the medium $\mathrm{pH}$ during growth are considered as efficient phosphate solubilizers (Halder et al., 1991).

According to HPLC analysis, gluconic acid was the major acids produced by all the tested bacteria strains followed by oxalic acid (Table 1). No strain was capable for production of citric acids. Among Burkholderia species PSB-2 produced the highest amount of gluconic acid $(7.98 \mathrm{mM})$ and oxalic acid $(0.117 \mathrm{mM})$ than other two species. In agreement with this work, gluconic acid was the major organic acid produced by Burkholderia cepacia DA23 (Song et al., 2008) Burkholderia cepacia CC-A174 (Lin et al., 2006) and it was detected maximum $9.4 \mathrm{mM}$ and $16.3 \mathrm{mM}$ respectively in the culture medium. Results revealed that organic acid production in the culture medium increased with the incubation period, reaching a maximum at 2-3 days. This finding was also evident from the $\mathrm{pH}$ decreased during the period of the increase of organic acids. Therefore, the production of organic acids played a significant role in the acidification of culture medium and following by the decrease of $\mathrm{pH}$ in culture medium and thus facilitated the inorganic phosphate solubilization.

Strains were tested for their ability to solubilize hardly soluble phosphate sources $\left(\mathrm{FePO}_{4}\right.$ and $\left.\mathrm{AlPO}_{4}\right)$ and results are shown in Fig. 3. The ability to solubilize $\mathrm{FePO}_{4}$ or $\mathrm{AlPO}_{4}$ by isolates was lower when compared with the $\mathrm{Ca}_{3}\left(\mathrm{PO}_{4}\right)_{2}$ solubilizing ability. Therefore, isolated Burkholderia species are not effective in solubilizing hardly soluble $\mathrm{Fe}$ and $\mathrm{Al}$ phosphate. This observation in consistent with earlier reports, which have shown that the very low Al phosphate solubilization by Burkholderia cepacia DA23 (Song et al., 2008). This may be probably due to the adaptive nature of the enzyme that is responsible

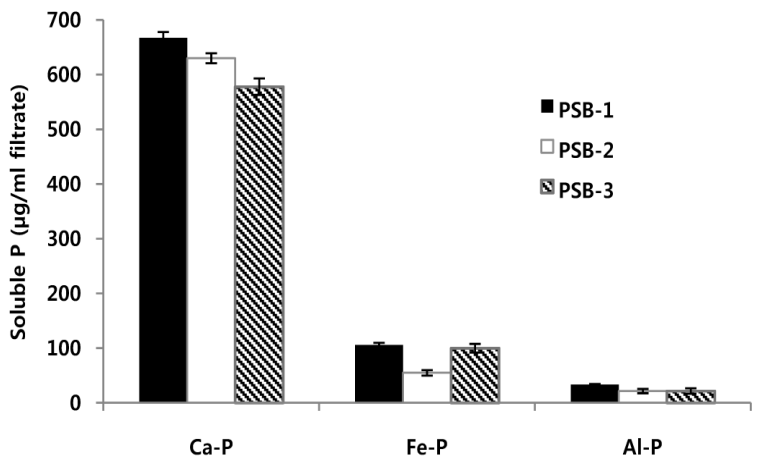

Fig. 3. Soluble phosphorus content under different phosphate sources (Ca-P : $\mathrm{Ca}_{3}\left(\mathrm{PO}_{4}\right)_{2}, \mathrm{Fe}-\mathrm{P}: \mathrm{FePO}_{4}$ and $\mathrm{Al}-\mathrm{P}$ : $\left.\mathrm{AIPO}_{4}\right)$. Results represent the mean of three replicates $\pm \mathrm{SD}$.

for solubilizing $\mathrm{Ca}_{3}\left(\mathrm{PO}_{4}\right)_{2}$ (Banik and Dey, 1982). However, a few reports have indicated the other soil microorganisms to solubilize hardly soluble $\mathrm{Fe}$ or $\mathrm{Al}$ phosphates (Barroso et al., 2006; Antoun, 2002). Penicillum rugulosum was more efficient for solubilizing $\mathrm{AlPO}_{4}$ and $\mathrm{FePO}_{4}$ than hydroxyapatite (Reyes et al., 1999).

Nutrition condition of the culture medium affects microbial growth as well as phosphate solubilization (Jain et al., 2012). Inorganic phosphate solubilizing capacity of PSB-1, PSB-2 and PSB-3 was assessed in the presence of eight carbon sources and five nitrogen sources by replacing glucose and $\left(\mathrm{NH}_{4}\right)_{2} \mathrm{SO}_{4}$ respectively in NBRIP medium (Table 2). All Burkholderia species showed diverse levels of phosphate solubilizing activity in the presence of various carbon and nitrogen sources.

The effect of various carbon sources on phosphate solubilization by Burkholderia species (Table 1) revealed that glucose was the preferred carbon source for all three Burkholderia species followed by galactose (PSB-1 : 88.9\%, PSB-2 : $93.8 \%$ and PSB-3 : 76.4\% when compared to the control). Xylose was found to be a poor source of carbon for all the species in solubilization of phosphate. The highest $\mathrm{pH}$ reduction was recorded by glucose (3.63, 3.82 and 3.93 respectively for PSB-1, PSB-2 and PSB-3) followed by other carbon sources. The nature of carbon sources affects the type and concentration of organic acid 
Table 2. Effect of various carbon and nitrogen sources on phosphate solubilization by PSB-1, PSB-2 and PSB-3.

\begin{tabular}{|c|c|c|c|}
\hline & \multicolumn{3}{|c|}{ Phosphate solubilization compared to control (\%) } \\
\hline & PSB-1 & PSB-2 & PSB-3 \\
\hline Control & $100(3.63)$ & $100(3.82)$ & $100(3.93)$ \\
\hline Absolute value & $665 \pm 12.5$ & $630 \pm 10.8$ & $578 \pm 14.5$ \\
\hline \multicolumn{4}{|l|}{ Carbon source } \\
\hline Fructose & $28.2(4.88)$ & $15.7(5.18)$ & $3.8(6.01)$ \\
\hline Galactose & $88.9(4.12)$ & $93.8(4.13)$ & $76.4(4.01)$ \\
\hline Sorbitol & $12.3(5.67)$ & $9.6(5.95)$ & $6.3(5.69)$ \\
\hline Mannitol & $32.7(5.01)$ & $33.5(5.81)$ & $19.2(5.59)$ \\
\hline Xylose & $3.1(6.28)$ & $4.4(5.62)$ & $2.5(6.26)$ \\
\hline Sucrose & $15.3(6.42)$ & $89.6(4.31)$ & $7.3(6.33)$ \\
\hline Maltose & $72.9(4.18)$ & $69.9(4.42)$ & $67.5(4.16)$ \\
\hline Lactose & $72.6(4.16)$ & $84.4(4.25)$ & $61.5(4.18)$ \\
\hline \multicolumn{4}{|l|}{ Nitrogen source } \\
\hline $\mathrm{NH}_{4} \mathrm{Cl}$ & $99.2(3.65)$ & 102.5 (3.93) & $100(3.75)$ \\
\hline $\mathrm{NH}_{4} \mathrm{NO}_{3}$ & $84.9(4.19)$ & $93.5(4.05)$ & 88.9 (4.33) \\
\hline $\mathrm{KNO}_{3}$ & $100(3.75)$ & 94.6 (3.96) & $97.2(3.76)$ \\
\hline $\mathrm{NaNO}_{3}$ & $94.1 \quad(3.82)$ & $100(3.83)$ & $82.7(3.82)$ \\
\hline $\mathrm{Ca}_{3}\left(\mathrm{NO}_{3}\right)_{2}$ & $99.8(3.78)$ & $99.8(3.78)$ & $92.5(3.85)$ \\
\hline
\end{tabular}

Control strains were grown for 3 days in NBRIP medium

Autoclaved, un-inoculated medium served as control. Final $\mathrm{pH}$ of the growth medium is given within the parentheses.

Absolute value of phosphate solubilization $\left(\mu \mathrm{g} \mathrm{ml}^{-1}\right)$ of control corresponding to $100 \%$. Values are means \pm SD for triplicates.

produced by the phosphate solubilizing microorganisms which in turn controls the amount of phosphate solubilization by lowering the $\mathrm{pH}$ and ability to chelate different metal ions that are associated with phosphate. Our results showed a significant negative correlation for soluble phosphorus and $\mathrm{pH}$ with all carbon sources. Corresponding to this result, it has been reported that glucose is the best carbon source for phosphate solubilization in Burkholderia vietnamiensis M6 (Park et al., 2010) and Burkholderia cepacia DA23 (Song et al., 2008).

To determine the effect of glucose concentration on the insoluble phosphate solubilization, various glucose concentrations ranging from $0.5 \%$ to $5 \%$ were added to the medium. As depicted in Fig. 4, phosphate solubilization was enhanced with increasing amounts of glucose up to $2 \%$ in PSB-1 and PSB-2 and up to 3\% in PSB-3, but beyond this limit, there was reduction in the level of phosphate solubilization. It has been reported that insoluble phosphate solubilization by was enhanced with increasing amounts of glucose up to $2.5 \%$ in Burkholderia vietnamiensis M6 (Park et al., 2010) and up to 3\% in Burkholderia cepacia DA23 (Song et al., 2008).

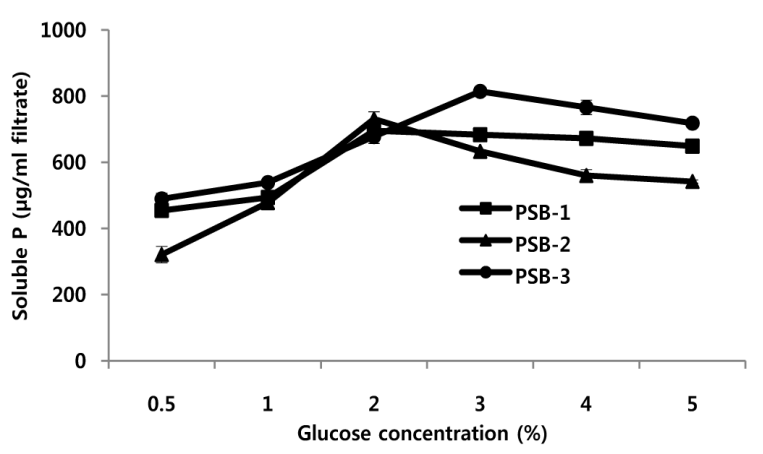

Fig. 4. Effect of glucose concentration on phosphate solubilization by PSB-1, PSB-2 and PSB-3. Values given here are the means of three replicates $(n=3)$.

Various ammonium and nitrate sources were added separately to the medium to assess their effects on phosphate solubilization and results are shown in Table 2. According to the results it is clear that ammonium and nitrate sources to be equally effective for phosphate solubilization PSB-1, PSB-2 and PSB-3. In agreement with this, Nautiyal et al. (2000) also observed all ammonium and nitrate sources were utilized for phosphate solubilization by NBRI0603, NBRI12601, NBRI13246 and NBRI14003 strains. However, there are some earlier 
Table 3. Effect of various pH, temperature and salt concentration ( $\mathrm{NaCl} \%$ ) on phosphate solubilization by PSB-1, PSB-2 and PSB-3.

\begin{tabular}{|c|c|c|c|}
\hline & \multicolumn{3}{|c|}{ Phosphate solubilization compared to control (\%) } \\
\hline & PSB-1 & PSB-2 & PSB-3 \\
\hline Control & $100(3.63)$ & $100(3.82)$ & $100(3.93)$ \\
\hline Absolute value & $665 \pm 12.5$ & $630 \pm 10.8$ & $578 \pm 14.5$ \\
\hline \multicolumn{4}{|l|}{ Initial $\mathrm{pH}$} \\
\hline 8 & $94.7(3.89)$ & $104.2(3.69)$ & $140.9(3.69)$ \\
\hline 9 & $88.6(4.06)$ & $106.3(3.83)$ & $129.9(3.74)$ \\
\hline 10 & $23.6(4.92)$ & $1.0(7.95)$ & $2.2(6.31)$ \\
\hline 11 & $0.7(8.91)$ & $0.9(8.63)$ & $1.2(6.96)$ \\
\hline 12 & $0.4(9.83)$ & $0.6(9.79)$ & $0.2(9.54)$ \\
\hline \multicolumn{4}{|l|}{ Temperature $\left({ }^{\circ} \mathrm{C}\right)$} \\
\hline 35 & $91.1(3.78)$ & $95.8(3.91)$ & $105.6(3.85)$ \\
\hline 40 & $22.3(4.58)$ & $27.7(4.53)$ & $20.3(6.41)$ \\
\hline \multicolumn{4}{|l|}{$\mathrm{NaCl}(\%)$} \\
\hline 2.5 & $87.3(4.13)$ & 76.9 (4.34) & $89.2(4.05)$ \\
\hline 5 & $1.8(6.51)$ & $2.0(6.65)$ & $2.4(6.79)$ \\
\hline 7.5 & $1.8(6.55)$ & $1.9(6.71)$ & $2.1(6.76)$ \\
\hline 10 & $1.8(6.53)$ & $1.7(6.76)$ & $1.9(6.75)$ \\
\hline
\end{tabular}

Control strains were grown for 3 days in NBRIP medium

Autoclaved, un-inoculated medium served as control. Final $\mathrm{pH}$ of the growth medium is given within the parentheses.

Absolute value of phosphate solubilization $\left(\mu \mathrm{g} \mathrm{ml}^{-1}\right)$ of control corresponding to $100 \%$. Values are means \pm SD for triplicates.

reports contrary to these findings showing differences in phosphate solubilization and also different mechanisms involving in acidity generation when ammonium and nitrate was used (Kpomblekou and Tabatabai, 1994; Halder et al., 1991). They have been reported that phosphate solubilization accelerates due to inorganic acids production by proton exchange mechanism in the presence of ammonium ion (Ahuja et al., 2007). However, Production of organic acids was greatly affected by carbon source not by nitrogen source. Therefore, organic acid production is not the sole factor responsible for phosphate solubilization.

The Burkholderia species were grown under high $\mathrm{pH}$ $(8,9,10,11$ and 12$)$, high temperature $\left(35\right.$ and $\left.40^{\circ} \mathrm{C}\right)$ and high salt $(2.5,5,7.5$ and $10 \% \mathrm{NaCl})$ conditions to study the effect of such conditions on the phosphate solubilizing ability of Burkholderia species (Table 3). The phosphate solubilizing abilities of the two strains (PSB-2 and PSB-3) were higher than the controls at the $\mathrm{pH} 8$ and 9. The amount of soluble phosphorus produced seemed to be lower with the increasing $\mathrm{pH}$ beyond 9, but PSB-1 showed $24 \%$ phosphate solubilizing ability at $\mathrm{pH} 10$ when compared to the control. This suggests that these bacteria favor alkaline conditions.
The phosphate solubilizing ability of the strain PSB-3 was higher than the control at the $35^{\circ} \mathrm{C}$ temperature. Even though the phosphate solubilizing activity was highest at $30^{\circ} \mathrm{C}$, other two strains also able to produce relatively high amount of soluble phosphorus at the $35^{\circ} \mathrm{C}$ temperature (91\% and $96 \%$ for PSB-1 and PSB-2 respectively when compared to the control). Generally bacteria growth was reduced at high temperature (Malboobi et al., 2009). This was more pronounced for our Burkholderia species such that phosphate solubilization dramatically decreased when incubated at $40^{\circ} \mathrm{C}$.

Even though a slight decrease observed in phosphate solubilization in all Burkholeria species, they could tolerate to added $\mathrm{NaCl}$ concentrations up to $2.5 \%$ suggests that isolates would be functionally active where salinity is below $2.5 \%$. In all cases except $2.5 \%$, there was a dramatical decrease in the production of soluble phosphorus with increasing concentrations of $\mathrm{NaCl}$.

In a similar study, Malbodi et al (2009) isolated Pantoea agglomerans $\mathrm{P} 5$, Microbacterium laevaniformans $\mathrm{P} 7$ and Pseudomonas putida $\mathrm{P} 13$ that could withstand $42^{\circ} \mathrm{C}$ temperature, wide range of $\mathrm{pH}$ (5-11) and high concentration of $\mathrm{NaCl}$ (up to 5\%) without much compromising the phosphate solubilization. 
Plant growth assay Plant growth promotion assay of strains showed that the all three Burkholderia species had significantly different effect on shoot and root growth when compared with uninoculated seeds. This may be due to enhanced phosphorus nutrition which affects overall plant growth and root development (Jones and Darrah, 1994). As shown in Fig. 5, it was observed that inoculated seedlings (PSB-1, PSB-2 and PSB-3 respectively) recorded $24.41 \%, 22.31 \%, 27.73 \%$ and $19.11 \%, 17.43 \%$, $30.11 \%$ higher shoot and root lengths respectively compared to uninoculated control. PSB-3 inoculated seedlings showed significant shoot and root growth when compared with PSB-1 and PSB-2 (Fig. 6).

It is clear from the results that the strain PSB-3 which demonstrated lower phosphorus release in the culture filtrate showed higher plant and root growth in the soil. Therefore, in addition to providing available phosphorus to plants, phosphate solubilizing microorganisms can enhance plant growth through several different mechanisms when inoculated in soil (Mundra et al., 2011). However, plant growth period was short and further works are required for their suitability as bio-inoculants.

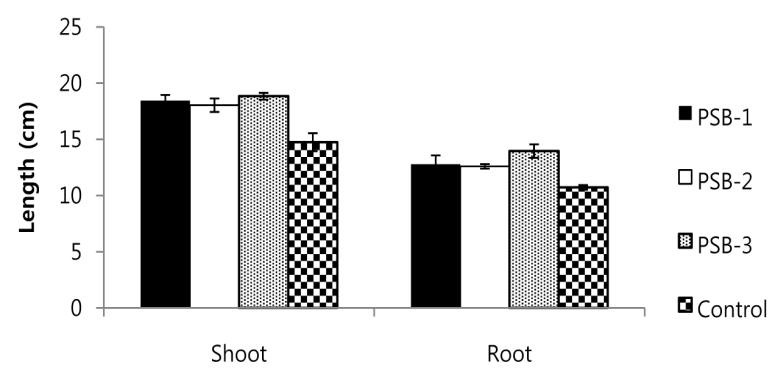

Fig. 5. Soot length and root length of green gram seedlings after inoculation of PSB-1, PSB-2 and PSB-3. Values given here are the means of three replicates $(n=3)$.

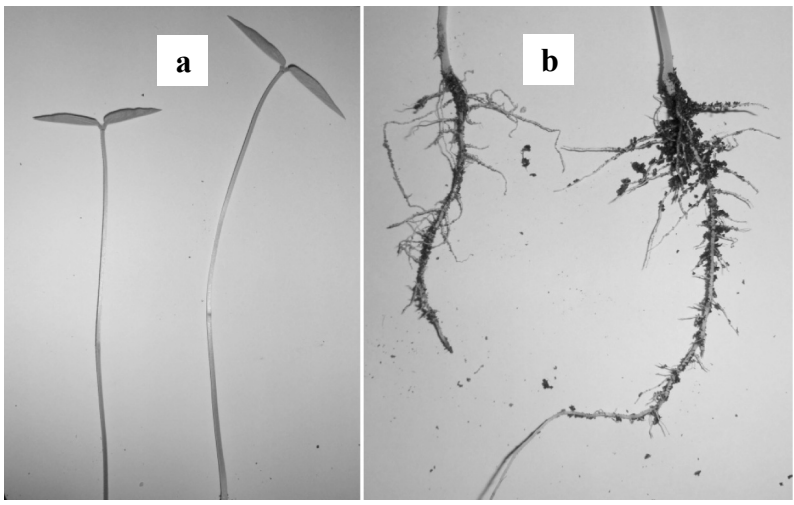

Fig. 6. Soot length (a) and root length (b) of control (left) and PSB-3 (right) inoculated green gram seedlings.

\section{References}

Ahuja, A., S.B. Ghosh, and S.F. D'Souza. 2007. Isolation of starch utilizing, phosphate solubilization fungus medium and its characterization. Bioresour. Technol. 98:3408-3411.

Antoun, H. 2002. Field and greenhouse trials performed with phosphate-solubilizing bacteria and fungi. In: First International meeting on microbial phosphate solubilization. Salamanca, Spain, 16-19 July, pp. 29-31

Banik, S. and B.K. Dey. 1982. Available phosphate content of an alluvial soil as influenced by inoculation of some isolated phosphate-solubilizing microorganisms. Plant Soil. 69:353-364.

Barroso, C.B., G.T. Pereira, and E. Nahas. 2006. Solubilization $\mathrm{CaHPO}_{4}$ and $\mathrm{AlPO}_{4}$ by Aspergillus niger in culture media with different carbon and nitrogen sources. Braz. J. Microbiol. 37: 434-443.

Chaiharn, M. and S. Lumyong. 2009. Phosphate solubilization potential and stress tolerance of rhizobacteria from rice soil in Nothern Thailand. World J. Microbiol. Biotechnol. 25:305-314.

Dave, A. and H.H. Patel. 2003. Impact of different carbon and nitrogen sources on phosphate solubilization by Pseudomonas fluorescens. Indian J. Microbiol. 43:33-36.

Fasim, F., N. Ahmed, R. Parson, and G. M. Gadd. 2002. Solubilization of zinc salts by a bacterium isolated from air environment of a tannery. FEMS Microbiol. Lett. 213:1-6.

Halder, A.K., A.K. Mishra, and P.K. Chakrabarty. 1991. Solubilization of inorganic phosphates by Bradirhizobium. Indian J. Exp. Biol. 29:28-31.

Jain, R., J. Saxena, and V. Sharma. 2012. Effect of phosphate solubilizing fungi Aspergillus awamori S29 on mungbean (Vigna radiata $\mathrm{cv}$. RMG 492) growth. Folia Microbiol. DOI 10.1007/s12223-012-0167-9.

Jones, D.L. and P.R. Darrah. 1994. Role of root derived organic acids in the mobilization of nutrients from the rhizosphere. Plant Soil. 66:247-257.

Kang, S.C., C.G. Ha, T.G. Lee, and D.K. Maheswari. 2002. Solubilization of insoluble inorganic phosphates by a soil-inhabiting fungus Fomitopsis sp. PS 102. Curr. Sci. 82:439-442.

Kim, Y.H., B. Bae, and Y.K. Choung. 2005. Optimization of biological phosphorus removal from contaminated sediments with phosphate solubilizing microorganisms. J. Biosci. Bioeng. 1:23-29.

Kpomblekou, K. and M.A. Tabatabai. 1994. Effect of organic acids on release of phosphorus from phosphate rocks. Soil Sci. 158:442-453.

Lin, T.F., H.I. Huang, F.T. Shen, and C.C. Young. 2006. The protons of gluconic acid are the major factor responsible for the dissolution of Tricalcium phosphate by Burkholderia cepacia CC-A174. Biores. Technol. 97:957-960.

Malboobi M.A., P. Owlia, M. Behbahani, E. Sarokhani, S. Moradi, B. Yakhchali, A. Deljou, and K. M. Heravi. 2009. Solubilization of organic and inorganic phosphates by three highly efficient soil bacterial isolates. World $\mathrm{J}$ Microbiol Biotechnol. 25:1471-1477. 
Mundra, S., R. Arora, and T. Stobdan, 2011. Solubilization of insoluble inorganic phosphates by a novel temperature, $\mathrm{pH}$ and salt tolerant yeast, Rhodotorula sp. PS4, isolated from seabuckthorn rhizosphere, growing in cold desert of Ladakh, India. World J. Microbiol. Biotechnol. 27:2387-2396.

Murphy, J. and J.P. Riley. 1962. A modified single solution method for the determination of phosphate in mineral waters. Anal. Chim. Acta. 27:31-36.

Nautiyal, C.S., S. Bhadauria, P. Kumar, H. Lal, R. Mondal, and D. Verma. 2000. Stress induced phosphate solubilization in bacteria isolated from alkaline soils. FEMS Microbiol. Lett. 182:291-296.

Park, K.H., O.M. Lee, H.I. Jung, J.H. Jeong, Y.D. Jeon, D.Y. Hwang, C.Y. Lee, and H.J. Son. 2010. Rapid solubilization of insoluble phosphate by a novel environmental stress-tolerant Burkholeria vietnamiensis M6 isolated from ginseng rhizospheric soil. Appl. Microbiol. Biotechnol. 86: 947-955.
Reyes, I., L. Bernier, R.R. Simard, and H. Antoun. 1999. Effect of nitrogen source on the solubilization of different inorganic phosphates by an isolate of Penicillium rugulosum and two UV induced mutants. FEMS Microbiol. Ecol. 28:281-290.

Song, O.R., S.J. Lee, Y.S. Lee, S.C. Lee, K.K. Kim, and Y.L. Choi. 2008. Solubilization of insoluble inorganic phosphate by Burkholderia cepacia DA 23 isolated from cultivated soil. Brazil J. Microbiol. 39: 151-156.

Vassilev, N., M. Vassileva, and I. Nikolaeva. 2006. Simultaneous P-solublilizing and bio-control activity of the microorganisms: Potential and future trends. Appl. Microbiol. Biotechnol. 71:n137-144.

Xiao, C., R. Chi, H. He, G. Qiu, D. Wang, and W. Zhang. 2009. Isolation of phosphate solubilizing fungi from phosphate mines and their effect on wheat seedling growth. Appl. Biochem. Biotechnol. 159:330-342. 